\section{ENGEVISTA}

Página da revista: http://www.uff.br/engevista/seer/

\title{
Sustentabilidade em Copas do Mundo: uma análise comparativa da emissão de gases do efeito estufa provenientes dos transportes e das demais infraestruturas
}

\author{
Rodrigo Pinheiro Tóffano Pereira ${ }^{1}$ \\ Glaydston Mattos Ribeiro ${ }^{2}$
}

Resumo: Este artigo tem por objetivo analisar a emissão de gases do efeito estufa oriundos da construção/reforma de estádios de futebol e da utilização da rede de transportes e demais infraestruturas das últimas três Copas do Mundo FIFA ${ }^{T M}$ Alemanha 2006, África do Sul 2010 e Brasil 2014. A apreciação que adotou a emissão de dióxido de carbono equivalente $\left(\mathrm{tCO}_{2} \mathrm{e}\right)$ como unidade comparativa, evidencia a contribuição majoritária do sistema de transportes, principalmente, decorrente de deslocamentos internacionais, na emissão de gases do efeito estufa. Esta característica indica a necessidade de uma reflexão acerca dos transportes envolvidos em grandes eventos esportivos.

Palavras-chave: Sustentabilidade, gases do efeito estufa, Copa do Mundo, transporte.

\footnotetext{
${ }^{1}$ UFRJ - Universidade Federal do Rio de Janeiro

${ }^{2}$ UFRJ - Universidade Federal do Rio de Janeiro
}

ENGEVISTA, V. 18, n. 2, p. 436-454, Dezembro 2016. 
Abstract: This paper aims to analyze the emission of greenhouse gases resulting from the construction/renovation of soccer stadiums and the use of the transportation network and other infrastructure of the last three FIFA World Cups ${ }^{T M}$ Germany 2006, South Africa 2010 and Brazil 2014. The appreciation adopted the emission of carbon dioxide equivalent $\left(\mathrm{tCO}_{2} \mathrm{e}\right)$ as unit comparative and shows the majority contribution is from the transport system, mainly due to international flights in the emission of greenhouse gases. This feature indicates the need for a reflection on the transportation involved in major sporting events.

Keywords: Sustainability, greenhouse gases, World Cups, transportation. 


\section{Introdução}

A busca pela sustentabilidade em grandes eventos esportivos é recente. Tendo como marco a assimilação dos preceitos da Eco-92, no Rio de Janeiro, pelo Comitê Olímpico Internacional (COI), em 1994 (IOC, 2009). Lillehammer, na Noruega, sede dos XVII Jogos Olímpicos de Inverno de 1994, foi a primeira cidade beneficiada; ao apresentar instalações energeticamente e ambientalmente eficientes (Tóffano, 2013). Todavia, apenas em 2006, a Federação Internacional de Futebol (FIFA) e seus parceiros, com os preparativos para a Copa do Mundo FIFA ${ }^{T M}$ Alemanha, introduziram políticas ambientais neste evento, por meio do Programa Green Goal ${ }^{T M}$ (FIFA, 2007).

O Green Goal $^{T M}$ foi lançado em 2005, em parceria inédita da FIFA com o Programa das Nações Unidas para o Meio Ambiente (PNUMA), a Federação Alemã de Futebol e o Ministério Alemão do Meio Ambiente, como forma de demonstrar que o esporte também pode contribuir com as questões de desenvolvimento sustentável. Em linhas gerais, o Programa prevê a administração racional da água e dos resíduos gerados, a economia de energia e o uso de sistemas públicos de transporte eficientes (OC, 2006).

Estas iniciativas vêm contribuindo para o acúmulo de conhecimentos e experiências para cidades-sede de grandes eventos esportivos, ao fornecer uma base sobre a qual poderão desenvolver seus próprios programas ambientais e de infraestrutura dentro das limitações impostas. De forma a minimizar as consequências negativas destes sobre o meio ambiente, maximizando o legado social, econômico e ambiental. Não só no período de sua realização, mas também no pós-evento.

Para lidar com este desafio, países anfitriões necessitam efetivar a correta gestão e redução das emissões de Gases do Efeito Estufa (GEE) das atividades, da infraestrutura e dos processos relacionados à concretização de seus eventos, que buscam esta sustentabilidade. Geralmente a compensação é decorrente de um cálculo do inventário das emissões destes gases e se dá por meio do plantio de mudas de árvores, em áreas degradadas. Durante o processo de preparação do país/cidade para os jogos, esta compensação, segundo Neto et al., (2011), também pode se dar por meio do investimento em novas tecnologias, materiais e instalações de ponta. São exemplo as edificações idealizadas com alto rigor ambiental, sejam estádios ou outras instalações, e a ampliação da infraestrutura de mobilidade e suprimento de energia de forma planejada e sustentável (investimentos estes, considerados de longo prazo).

Tendo em vista a complexidade envolvida na organização de grandes eventos esportivos de forma sustentável, este artigo tem como objetivo indicar quais seriam os maiores contribuintes da emissão de GEE, em Copas do Mundo. Levando em consideração os dados dos últimos três Mundiais (Alemanha-2006, África do Sul-2010 e Brasil-2014), os seguintes elementos foram considerados na análise: 
- Emissão de GEE proveniente da construção/reforma de novas arenas/estádios de futebol;

- Emissão de GEE associado à infraestrutura (materiais, energia, etc.) necessária durante os 30 dias médios do evento; e

- Emissão de GEE proveniente da utilização dos sistemas de transporte (desde o deslocamento terrestre ao aéreo nacional e internacional), efetuado por seus torcedores e comissões técnicas (jogadores, técnicos, dirigentes e etc).

Busca-se deixar evidente, nos três casos, a diferença do volume de GEE oriundo da utilização do sistema de transportes e da construção/reforma de novas arenas/estádios, para um ciclo de vida de 30 anos. Leva-se em conta, também, a diferente realidade desenvolvimentista, econômica, social e da matriz energética destes países. Pois, estas características indicam diferentes domínios de técnicas construtivas e de formas de planejamento, fundamentais para o entendimento das questões propostas. Assim como, das suas dispares dimensões territoriais, para o tratamento dos diversos dados desta pesquisa. O aprofundamento nestas questões, com o entendimento e a divulgação de seus valores correspondentes, estimulará, certamente, a implementação e o planejamento de eventos mais sustentáveis; ao reduzir seus aspectos negativos e potencializar os positivos, em prol da sociedade, das gerações futuras e do meio ambiente.

O artigo está estruturado como segue. A Seção 2 descreve, sucintamente, os megaeventos sustentáveis. Em seguida, a Seção 3 apresenta os GEE, alguns métodos utilizados na quantificação e a relação desses gases com grandes eventos esportivos. Na Seção 4, em cada uma das Copas do Mundo, em análise são apresentados os elementos em destaque, anteriormente, com seus respectivos valores absolutos. Na Seção 5, os resultados e discussões são mostrados. E por fim, as considerações finais ratificam o trabalho de pesquisa.

\section{Sustentabilidade em megaeventos esportivos}

A busca pela sustentabilidade é objeto de estudos científicos há décadas, contemplando pesquisas desde a origem de seu conceito, até a sua aplicação na economia, na engenharia, na geografia, dentre outros. Ao tratar deste assunto, uma das metodologias mais aceitas, para determinar o conceito de desenvolvimento sustentável, já que sua interpretação não é universal, é aquela que a define como o equilíbrio do tripé formado por aspectos ambientais, socioculturais e econômicos (Bismarchi, 2011). Ou seja, o que é ecologicamente correto, socialmente justo, economicamente viável e culturalmente aceito. Neste caso, para ser sustentável, um grande evento esportivo deve gerenciar seus riscos de forma a impedir a degradação ambiental, gerar a distribuição de riqueza entre as diversas camadas e setores da sociedade, incluindo-se aí o próprio empreendedor, e evitar o empobrecimento das futuras gerações, além de atender as necessidades individuais (Neto et al., 2011). Por exemplo, Gossling et al. (2002) mostram que o transporte é o responsável pela maior 
parte dos impactos ambientais ligados ao turismo de longa distância e é exatamente neste setor que estão incluídos os grandes eventos esportivos.

Diversas soluções e instrumentos estão disponíveis no mercado para a realização de um evento sustentável, dentre as quais se destacam padrões e processos internacionalmente aceitos e reconhecidos, certificações e melhores práticas. Entretanto, pela ausência de um método comum de práticas sustentáveis, as certificações ambientais acabaram se tornando uma referência para que diretrizes ambientais fossem adotadas e avaliadas, pelas empresas, em seus projetos Green Buildings. Expressão esta utilizada, a partir da década de 1990, para englobar todas as iniciativas dedicadas à criação de construções mais eficientes do ponto de vista energético, mais confortáveis e passíveis de adaptações (Silva, 2007).

Diversos países já desenvolveram suas próprias metodologias de avaliação da sustentabilidade ambiental de edificações. Selos/certificações que se tornaram símbolos de um marketing ambiental de vendas e de divulgação de produtos arquitetônicos que foram adotados pela FIFA e por diversos outros organismos esportivos mundiais de forma a contemplar a preocupação ambiental com grande parte dos empreendimentos a serem edificados, ou reformados para seus megaeventos. Entretanto, nenhuma avaliação/certificação específica foi desenvolvida para considerar um estádio e/ou um megaevento esportivo como 100\% sustentável (Tóffano, 2013). Segundo Collins et al. (2009), a quantificação dos impactos de grandes eventos, no meio ambiente, se tornará cada vez mais importante; se incorporando como um compromisso do desenvolvimento sustentável por parte das constituições e declarações de organizações esportivas e de estatutos dos órgãos públicos.

No entanto, uma das formas mais difundidas de medir a sustentabilidade de um evento esportivo, de forma a comparar diferentes itens tais como transporte, obras civis e infraestrutura, é por meio da quantificação de GEE e a sua possível compensação, através do status de carbono neutro, ou em inglês, carbon free. Sua quantificação e seu inventário, além de cumprir um importante papel ambiental, promovem um grande impacto positivo do ponto de vista do marketing, ao propiciar medidas mitigadoras dos impactos ambientais gerados.

Uma das primeiras entidades esportivas internacionais a reconhecer sua responsabilidade com a promoção do meio ambiente e do desenvolvimento sustentável foi o COI, após protestos nos XVI Jogos Olímpicos de Inverno de Albertville, na França, em 1992, decorrentes da degradação do meio ambiente e da qualidade de vida da população local (Polokwane Municipality, 2009). Isso resultou na inclusão do meio ambiente como uma das dimensões integrantes do espírito olímpico, ao lado do esporte e da cultura (IOC, 2009). Com a sua adoção pela FIFA, em 2006, por meio do Programa Green Goal $^{T M}$, cada país sede de Copa do Mundo ou Olimpíada passou a criar seus próprios objetivos e projetos adaptados para a realidade e contexto local, de forma a minimizar a emissão de GEE e fazer com que seu evento seja o mais sustentável possível. 


\section{Metodologia empregada para cálculo da emissão de GEE em mundiais}

Conforme o Protocolo de Kyoto (ONU, 2005), a emissão de alguns GEE oriundos de atividades antrópicas é nociva a camada atmosférica. Dentre estes gases destacam-se o dióxido de carbono $\left(\mathrm{CO}_{2}\right)$, o óxido nitroso $\left(\mathrm{N}_{2} \mathrm{O}\right)$, o metano $\left(\mathrm{CH}_{4}\right)$, os perfluorocarbonos (PFCs), os hidroclorofluorcarbonos (HFCs) e o hexafluoreto de enxofre $\left(\mathrm{SF}_{6}\right)$. Estas emissões de GEE são, comumente, contabilizadas por meio da unidade de medida toneladas de $\mathrm{CO}_{2}$ equivalente $\left(\mathrm{tCO}_{2} \mathrm{e}\right)$.

Assim, em prol de um evento cada vez mais sustentável, todas as atividades preparatórias relevantes para as Copas do Mundo FIFA ${ }^{T M}$ de 2006, na Alemanha, de 2010, na África do Sul e de 2014, no Brasil, tiveram, por seus organizadores, suas emissões de GEE em $\mathrm{tCO}_{2}$ e contabilizadas de forma a aferir os impactos ambientais gerados. A contabilização destas emissões de GEE em Copas do Mundo é reproduzida neste trabalho, por meio de três metodologias distintas descritas de forma condensada, a seguir (Figura 1). Primeiramente: a construção/reforma de estádios/arenas esportivas; segundo, a infraestrutura necessária para a manutenção/realização do evento (em média 30 dias); por fim, a emissão de GEE proveniente da utilização dos sistemas de transporte, efetuado por seus torcedores e participantes. Busca-se compará-las e discuti-las para que estas possam vir a se tornar um índice, uma base, para a organização de novos megaeventos.

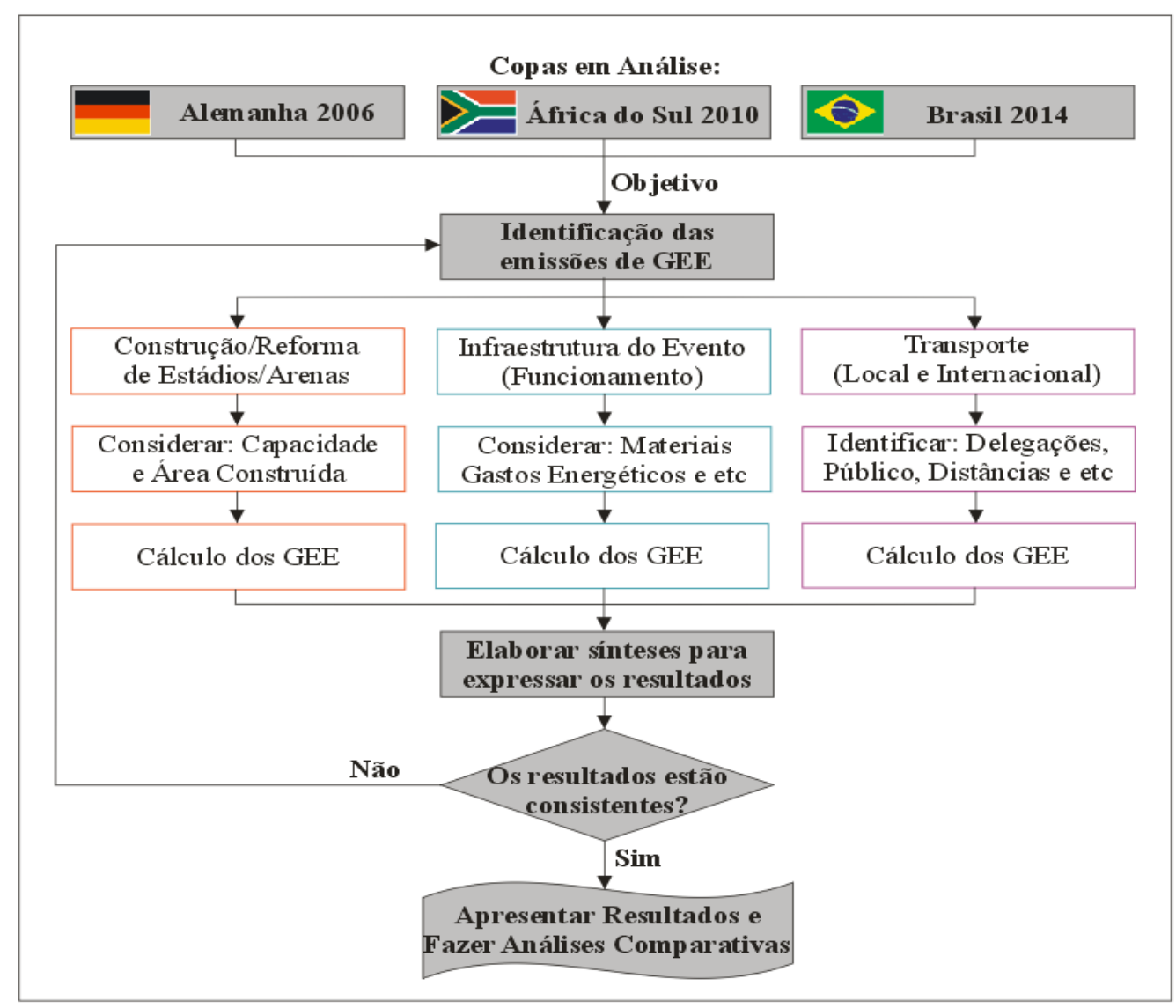

Figura 1: Síntese da metodologia proposta. 


\section{Construções e Reformas de Arenas}

Inicialmente, para se calcular a contribuição de GEE dos estádios brasileiros foi considerada sua área construída, em m², multiplicada por um fator de emissão de $0,29 \mathrm{~kg} / \mathrm{m}^{2}$ - estabelecido por CO2Zero (2012), em sua metodologia, para um ciclo de vida de 30 anos, conforme Equação (1).

\section{(1) Arenas $2014\left(\mathrm{tCO}_{2} \mathrm{e}\right)=$ Área $\left(\mathrm{m}^{2}\right) \times 0,29 \mathrm{~kg} / \mathrm{m}^{2}$}

Em seguida, em função de não terem sido encontradas as áreas correspondentes das arenas da Alemanha e da África do Sul, calculou-se uma média das emissões de $\mathrm{CO}_{2} \mathrm{e}$ das arenas utilizadas em 2014 para servir de parâmetro. Assim, dividiu-se o total das emissões dos doze estádios utilizados no Brasil, em 2014, pelo número total de assentos. Este fator, igual a $0,86 \mathrm{~kg}$, foi utilizado para o cálculo das emissões de GEE dos demais estádios utilizados nas Copas de 2006 e 2010, em função de suas capacidades de público, conforme Equação (2).

\section{(2) Arenas 2006/2010 $\left(\mathrm{tCO}_{2} \mathrm{e}\right)=$ Número de Assentos x 0,86 kg/assento}

\section{Infraestrutura do Evento}

Para calcular a contribuição de GEE das demais infraestruturas necessárias para a realização de uma Copa do Mundo, outro dado levantado na bibliografia, para estádios, foi o da emissão de GEE durante a sua utilização, nos trinta dias médios destes eventos; assim como, da energia desprendida para sua iluminação e das vias do entorno, por exemplo. Estes dados foram compilados de: Hochfeld, Stahl, Schmied (2006); Econ Pöyry AB (2009); Ernst \& Young (2010); Neto et al. (2011) e CO2Zero (2012). De forma sucinta, este cálculo complexo, que pode ser contemplado de forma mais aprofundada em suas obras originais, utiliza como base o consumo médio por assento, projetado por arena. De forma a facilitar a compreensão do artigo este e o próximo item, Transportes, são apresentados juntos, na próxima Seção, com o título “Transportes e Demais Infraestruturas".

\section{Transportes}

Por fim, para os transportes, também com base em Focus (2006); Hochfeld, Stahl, Schmied (2006); Econ Pöyry AB (2009); Ernst \& Young (2010); Neto et al. (2011) e CO2Zero (2012), dois tipos de público foram considerados neste cálculo. O primeiro referente a cada uma das 32 delegações participantes. Neste caso, um total de 45 pessoas foram consideradas por país participante, totalizando 1440 pessoas entre atletas, comissões técnicas e dirigentes. Já o público presente, em estádios, destes eventos, foi considerado de acordo com a expectativa de cada Ministério do Turismo correspondente; e a distribuição de estrangeiros seguiu a mesma proporção de vagas, por continentes, definidas para cada uma destas Copas. Para a Alemanha-2006, aproximadamente, um milhão de turistas estrangeiros eram esperados (Focus, 2006); para a África do Sul-2010, 400 mil turistas (Ernst $\&$ Young, 2010) e para o Brasil-2014, 600 mil turistas estrangeiros (CO2Zero, 2012). 
Para o cálculo das emissões de voos internacionais, considerou-se a distância média dos principais aeroportos de cada continente participante de cada uma das Copas para os principais aeroportos de cada país-sede: Aeroporto de Frankfurt, na Alemanha, em 2006; Aeroporto Internacional Oliver Tambo, em Johanesburgo, na África do Sul, em 2010; e Aeroporto Internacional de São Paulo, em Guarulhos, no Brasil, em 2014.

O deslocamento intercidades (voos dentro de cada um dos três países sede) considerou trechos aéreos quando estes eram possíveis, respeitando a distância entre as cidades-sede dos jogos de cada grupo, bem como a distância entre os destinos conforme resultado de chaveamento das fases de grupo, oitavas, quartas, semifinais e finais, e o número de delegações presentes em cada uma das fases. Para o público, as viagens no Brasil entre cidades-sede foram consideradas sendo realizadas por modo aéreo. Na África do Sul e na Alemanha em alguns casos, pela proximidade das cidades, o modo terrestre de deslocamento foi considerado. Segundo CO2Zero (2012), um turista estrangeiro, em média, se desloca por quatro cidades, em um Mundial. Moradores destes três países que se deslocaram, internamente, em seu próprio território nacional, também foram considerados com suas peculiaridades.

Esta preocupação em abordar aspectos do transporte/construção civil relacionados com o uso de energia e os impactos ambientais, em especial com a emissão de gases de efeito estufa se torna relevante. Ora, por tratar de questões relacionadas ao desenvolvimento sustentável de qualquer país a sediar um grande evento esportivo mundial; ora, por se ater a um objeto de estudo delimitado: os avanços na preocupação da gestão de poluentes em Mundiais da FIFA. Por esta contemporaneidade, esta temática ainda é pouco explorada e abordada parcialmente nos principais meios de divulgação acadêmica internacional. Espera-se, com esta pesquisa, avançar no acompanhamento de um processo de transformação positiva nos índices de sustentabilidade voltados para o esporte. Fato que se acentuará nos próximos anos, para os Mundiais de 2018, na Rússia, e de 2022, no Qatar, e que beneficiará a pesquisa e o trabalho de engenheiros, arquitetos, urbanistas e dos mais diversos profissionais envolvidos com as preocupações do meio ambiente e as questões construtivas e de transporte.

\section{As Copas do Mundo FIFA ${ }^{T M} 2006,2010$ e 2014}

A seguir, conforme o foco deste trabalho, são apresentadas as emissões de GEE de cada uma das arenas construídas e/ou reformadas para os três últimos mundiais, sua respectiva infraestrutura, assim como, da emissão oriunda da utilização dos sistemas de transportes.

\subsection{Copa do Mundo FIFA ${ }^{T M}$ Alemanha 2006}

A Copa do Mundo FIFA ${ }^{T M}$ Alemanha 2006 foi a décima oitava edição do torneio, tendo pela segunda vez a Alemanha como anfitriã (a primeira foi em 1974). Sessenta e quatro jogos foram disputados por 32 países, entre os dias 09 de junho e 09 de julho de 2006. O público total do evento 
foi de aproximadamente 3,4 milhões de pessoas e as 64 partidas tiveram uma média de aproximadamente 52 mil torcedores.

\section{Construções e Reformas de Arenas}

Doze cidades alemãs foram anfitriãs e disponibilizaram cada uma um estádio, com custo médio de US\$ 173 milhões, conforme a Tabela 1. Esta mesma Tabela apresenta os resultados das emissões de GEE conforme as cidades-sede considerando a capacidade de cada Estádio e o fator de $0,86 \mathrm{~kg} /$ assento, conforme descrito na Seção 3. Verifica-se que o custo total por assento foi de US\$ 3.245,36 e que $549.597 \mathrm{tCO}_{2} \mathrm{e}$ foram emitidas, gerando uma média de $45.800 \mathrm{tCO}_{2} \mathrm{e}$ por Arena, em um ciclo de vida de trinta anos.

\section{Transportes e Demais Infraestruturas}

A Alemanha apresenta um território nacional de pequeno porte com $357.051 \mathrm{~km}^{2}$ de área, se comparado ao Brasil e a África do Sul, mas amplamente servido por transportes de massa, principalmente trens, metrôs e trens de alta velocidade; conectados aos principais países europeus. Segundo o Gabinete de Informação de Transportes e Meio Ambiente da Alemanha (Focus, 2006), aproximadamente, 2,1 milhões de toneladas de $\mathrm{CO}_{2} \mathrm{e}$ foram liberadas, durante o Mundial, por seus espectadores nacionais e internacionais em deslocamentos. A Tabela 2 apresenta um detalhamento maior dos dados de transporte por nível nacional e internacional; nela também, podem ser encontrados os valores correspondentes as demais infraestruturas necessárias para a realização da Copa do Mundo de 2006. 
Tabela 1: Contribuição das emissões de $\mathrm{CO}_{2} \mathrm{e}$, por estádio, na Alemanha 2006.

\begin{tabular}{|c|c|c|c|c|c|c|}
\hline & Cidade & Estádio/Arena & $\begin{array}{c}\text { Capacidade } \\
\text { (pessoas) }\end{array}$ & $\begin{array}{c}\text { Tipo de } \\
\text { Constru- } \\
\text { ção }\end{array}$ & $\begin{array}{l}\text { Custo } \\
\text { (US\$) }\end{array}$ & $\begin{array}{c}\text { Emissões } \\
(\text { tCO } \\
\text { ee })\end{array}$ \\
\hline 01 & Berlin & Olympiastadion & 74.244 & Reforma & 330 milhões & 63.850 \\
\hline 02 & Colônia & RheinEnergieStadion & 46.134 & Reforma & 157 milhões & 39.675 \\
\hline 03 & Dortmund & Signal Iduna Park & 65.718 & Reforma & 264 milhões & 56.517 \\
\hline 04 & Frankfurt & Waldstadion & 48.132 & Novo & 166 milhões & 41.394 \\
\hline 05 & Gelsenkirchen & Veltins-Arena & 53.473 & Novo & 253 milhões & 45.987 \\
\hline 06 & Hamburgo & Aol Arena & 51.500 & Reforma & 132 milhões & 44.290 \\
\hline 07 & Hanôver & AWD-Arena & 43.000 & Reforma & 85 milhões & 36.980 \\
\hline 08 & Kaiserslautern & Fritz-Walter-Stadion & 43.450 & Reforma & 101 milhões & 37.367 \\
\hline 09 & Leipzig & Zentralstadion & 44.300 & Novo & 127 milhões & 38.098 \\
\hline 10 & Munique & Allianz-Arena & 69.901 & Novo & 307 milhões & 60.115 \\
\hline 11 & Nuremberg & Frankenstadion & 44.308 & Reforma & 75 milhões & 38.105 \\
\hline \multirow[t]{3}{*}{12} & Stuttgart & Gottlieb-Daimler & 54.906 & Reforma & 77 milhões & 47.219 \\
\hline & Total & $\begin{array}{l}12 \text { Arenas/ } \\
12 \text { Cidades }\end{array}$ & 639.066 & $\begin{array}{c}8 \\
\text { Reformas } \\
4 \text { Novos }\end{array}$ & $\begin{array}{c}2.074 \\
\text { bilhões }\end{array}$ & 549.597 \\
\hline & Média & - & 53.256 & - & $173 \mathrm{mil}$ & 45,8 \\
\hline
\end{tabular}

Fonte: Adaptado de Hochfeld, Stahl, Schmied (2006) e Tóffano (2013).

Tabela 2: Emissões de $\mathrm{CO}_{2} \mathrm{e}$ de transportes e demais infraestruturas da Copa 2006.

\begin{tabular}{l|c}
\hline \multicolumn{1}{c}{ Emissões Estimadas (toneladas de $\left.\mathbf{C O}_{2} \mathbf{e}\right)$} & Alemanha 2006 \\
\hline Setores & $2.027 .320^{(1)}$ \\
\hline $\begin{array}{l}\text { Transporte Internacional } \\
\text { (Para deslocamentos até o território do país-sede). }\end{array}$ & $72.680^{(2)(3)}$ \\
\hline $\begin{array}{l}\text { Transporte Local } \\
\text { (Para deslocamentos dentro do território do país-sede). }\end{array}$ & $4.600^{(2)(3)}$ \\
\hline $\begin{array}{l}\text { Construção } \\
\text { (Utilização de estádios e infraestrutura no período da Copa do Mundo). }\end{array}$ & $2.760^{(2)(3)}$ \\
\hline $\begin{array}{l}\text { Consumo de energia } \\
\text { (Estádios e infraestrutura no período da Copa do Mundo) }\end{array}$ & $\mathbf{2 . 1 0 7 . 3 6 0}$ \\
\hline Total das emissões com transportes e demais infraestruturas &
\end{tabular}

Fonte: Adaptada de ${ }^{(1)}$ Focus (2006); ${ }^{(2)}$ Hochfeld et al. (2006); ${ }^{(3)}$ Neto, et al. (2011).

A respeito da política governamental alemã, esta enfatiza a conservação e o desenvolvimento de fontes renováveis, no entanto, sua matriz energética ainda tem como principais fontes o petróleo, o carvão, o gás natural e a energia nuclear (OC, 2006). Este país europeu foi o pioneiro na busca pela sustentabilidade e de exemplos de boas práticas em uma Copa do Mundo, ao implantar, até então, o inédito Programa Green Goal ${ }^{T M}$ como base de suas atividades e dos seus preparativos para 2006. A Alemanha assumiu metas nas áreas de mudanças climáticas, mobilidade, energia, reuso de água e resíduos, como pode ser acompanhado em Green Goal - Legacy Report FIFA World Cup 2006 (OC, 2006). Prezou pelo correto planejamento, com equipe técnica para alcançar tais metas. Um dos maiores legados do torneio foi decorrente de projetos na área de mobilidade e do incentivo ao uso de transporte público, principalmente, em função da grande oferta destes.

Para compensar a emissão de GEE, investimentos financiados pela FIFA e pela Federação Alemã de Futebol foram realizados em três projetos diferentes, com cunho social e ambiental, em regiões carentes da Índia e da África do Sul, ao custo de 1,2 milhões de dólares para neutralizar 100.000 toneladas de $\mathrm{CO}_{2}$, ao longo dos próximos anos (Hochfeld et al., 2006). 


\subsection{Copa do Mundo FIFA ${ }^{T M}$ África do Sul 2010}

A Copa do Mundo FIFA ${ }^{T M}$ África do Sul 2010 foi a $19^{\mathrm{a}}$ edição do torneio, tendo pela primeira vez uma sede no continente africano. Sessenta e quatro jogos foram disputados por 32 países, entre os dias 11 de junho e 11 de julho. O público total do evento foi de 3.178 .856 pessoas e as 64 partidas tiveram uma média de 49.669 torcedores por arena.

\section{Construções e Reformas de Arenas}

Nove cidades sul-africanas foram anfitriãs e disponibilizaram um estádio, cada uma, com exceção de Johanesburgo, que disponibilizou dois: o Soccer City Stadium e o Ellis Park Stadium. O custo médio de cada uma das dez arenas foi de US\$ 204 milhões (Tabela 3), onde cada assento custou, aproximadamente, US\$3.652,85, e emitirão, em um ciclo de vida de 30 anos, conforme descrito na Seção 3, uma média de 47,9 toneladas de $\mathrm{CO}_{2} \mathrm{e}$.

\section{Transportes e Demais Infraestruturas}

A África do Sul apresenta um território nacional de médio-porte com $1.221 .037 \mathrm{~km}^{2}$ de área, mas extremamente dependente do sistema rodoviário e aéreo para grandes deslocamentos, pela baixa oferta de transportes de massa, principalmente trens, metrôs e trens de alta velocidade. A matriz energética ainda tem como principal fonte os combustíveis fósseis, sobretudo o carvão, que contribui de forma significativa no aumento das emissões de GEE. A Tabela 4 apresenta um detalhamento maior dos dados de transporte por nível nacional e internacional. Nela também podem ser encontrados os valores correspondentes as demais infraestruturas necessárias para a realização desta Copa.

Movida pelo sucesso do Programa Green Goal ${ }^{T M}$ alemão, a África do Sul buscou a sustentabilidade de seu evento, mesmo com as limitações naturais de um país em desenvolvimento. Diferentemente, de 2006, não houve um envolvimento de entidades especializadas, ficando a responsabilidade dos projetos verdes a cargo de cada uma das cidades envolvidas, em parceria com o Governo Federal e o Departamento de Assuntos Ambientais. Das cidades que se envolveram, o maior destaque sul-africano de avanços com o Programa Green Goal ${ }^{T M}$ foi da Cidade do Cabo, no extremo sul do país, que traçou e alcançou um número maior de metas de mitigação (Econ Pöyry $\mathrm{AB}, 2009)$.

Pelo tamanho do território, da maior distância média entre as sedes, do maior aporte de obras básicas e de infraestrutura, assim como dos deslocamentos centrados em estradas e por meio de voos (altos consumidores de combustíveis fósseis), as emissões de 2010 foram superiores, em toneladas de $\mathrm{CO}_{2}$ e, que as do Mundial de 2006. Estas emissões, para serem neutralizadas, custariam entre 6,8 e 12 milhões de dólares, sendo, portanto inviável pela falta de disponibilidade de financiamento e de recursos, em um país com tantas desigualdades sociais como a África do Sul (Econ Pöyry AB, 2009). 
Tabela 3: Contribuição das emissões de $\mathrm{CO}_{2}$ e, por estádio, na África do Sul 2010.

\begin{tabular}{|c|c|c|c|c|c|c|}
\hline & Cidade & Estádio/Arena & $\begin{array}{c}\text { Capacidade } \\
\text { (pessoas) }\end{array}$ & $\begin{array}{c}\text { Tipo de } \\
\text { Construção }\end{array}$ & Custo (US\$) & $\begin{array}{c}\text { Emissões } \\
\left(\text { tCO}_{2} \mathrm{e}\right)\end{array}$ \\
\hline 01 & Bloemfontein & Free State Stadium & 45.058 & Reforma & 24.7 milhões & 38.750 \\
\hline 02 & Cidade do Cabo & Green Point Stadium & 66.000 & Nova & 609 milhões & 56.760 \\
\hline 03 & Durban & Moses Mabhida Stadium & 62.760 & Nova & 450 milhões & 53.974 \\
\hline \multirow[t]{2}{*}{04} & Johanesburgo & Ellis Park Stadium & 61.639 & Reforma & 4,6 milhões & 53.010 \\
\hline & Johanesburgo & Soccer City Stadium & 94.787 & Reforma & 440 milhões & 81.517 \\
\hline 05 & Nelspruit & Mbombela Stadium & 43.589 & Nova & 140 milhões & 37.487 \\
\hline 06 & Polokwane & Peter Mokaba Stadium & 41.733 & Nova & 150 milhões & 35.890 \\
\hline 07 & Porto Elizabeth & Nelson Mandela Bay & 48.459 & Nova & 159 milhões & 41.675 \\
\hline 08 & Pretória & Loftus Versfeld Stadium & 49.365 & Reforma & 13.2 milhões & 42.454 \\
\hline \multirow[t]{3}{*}{09} & Rustemburgo & Royal Bafokeng Stadium & 44.530 & Reforma & 48 milhões & 38.296 \\
\hline & Total & $\begin{array}{l}10 \text { Arenas/ } \\
9 \text { Cidades }\end{array}$ & 557.920 & $\begin{array}{l}5 \text { Reformas } \\
5 \text { Novos }\end{array}$ & 2.038 bilhões & 479.811 \\
\hline & Média & - & 55.792 & - & $204 \mathrm{mil}$ & 47,9 \\
\hline
\end{tabular}

Fonte: Adaptado de Econ Pöyry AB (2009), CO2Zero (2012) e Tóffano (2013).

Tabela 4: Emissões de $\mathrm{CO}_{2}$ e de transportes e demais infraestruturas da Copa 2010.

\begin{tabular}{l|c}
\multicolumn{1}{c}{ Emissões Estimadas (toneladas de $\left.\mathbf{C O}_{2} \mathbf{e}\right)$} & África do Sul 2010 \\
\hline Setores & 1.856 .589 \\
\hline $\begin{array}{l}\text { Transporte Internacional } \\
\text { (Para deslocamentos até o território do país-sede). }\end{array}$ & 524.538 \\
\hline $\begin{array}{l}\text { Transporte Local } \\
\text { (Para deslocamentos dentro do território do país-sede). }\end{array}$ & 15.359 \\
\hline $\begin{array}{l}\text { Construção } \\
\text { (Utilização de estádios e infraestrutura no período da Copa do Mundo). }\end{array}$ & 16.637 \\
\hline $\begin{array}{l}\text { Consumo de energia } \\
\text { (Estádios e infraestrutura no período da Copa do Mundo) }\end{array}$ & $\mathbf{2 . 4 1 3 . 1 2 3}$ \\
\hline Total das emissões com transportes e demais infraestruturas &
\end{tabular}

Fonte: Adaptado de Econ Pöyry AB (2009) e Ernst \& Young (2010).

Tabela 5: Contribuição das emissões de $\mathrm{CO}_{2} \mathrm{e}$, por estádio, no Brasil 2014.

\begin{tabular}{|c|c|c|c|c|c|c|c|}
\hline & Cidade & Estádio/Arena & $\begin{array}{c}\text { Capacidade } \\
\text { (pessoas) }\end{array}$ & $\begin{array}{c}\text { Área } \\
\left(\mathbf{m}^{2}\right)\end{array}$ & $\begin{array}{c}\text { Tipo de } \\
\text { Construção } \\
\end{array}$ & Custo (US\$) & $\begin{array}{c}\text { Emissões } \\
\left(\mathrm{tCO}_{2} \mathrm{e}\right) \\
\end{array}$ \\
\hline 01 & $\begin{array}{l}\text { Belo } \\
\text { Horizonte }\end{array}$ & Estádio do Mineirão & 64.000 & 209.000 & Reforma & 305.5 milhões & 60.610 \\
\hline 02 & Brasília & Estádio Nacional & 71.400 & 214.000 & Novo & 615.5 milhões & 62.060 \\
\hline 03 & Cuiabá & Arena Pantanal & 43.136 & 101.400 & Novo & 250.6 milhões & 29.406 \\
\hline 04 & Curitiba & Arena da Baixada & 42.000 & 124.000 & Reforma & 143.3 milhões & 35.960 \\
\hline 05 & Fortaleza & Estádio Castelão & 63.903 & 162.000 & Reforma & 227.7 milhões & 46.980 \\
\hline 06 & Manaus & Arena da Amazônia & 44.000 & 170.000 & Novo & 294.1 milhões & 49.300 \\
\hline 07 & Natal & Arena das Dunas & 42.623 & 120.000 & Novo & 185.9 milhões & 34.800 \\
\hline 08 & $\begin{array}{l}\text { Porto } \\
\text { Alegre }\end{array}$ & Estádio Beira-Rio & 52.000 & 171.082 & Reforma & 145.1 milhões & 49.614 \\
\hline 09 & Recife & Arena Pernambuco & 46.160 & 129.000 & Novo & 233.9 milhões & 37.410 \\
\hline 10 & $\begin{array}{l}\text { Rio de } \\
\text { Janeiro }\end{array}$ & $\begin{array}{l}\text { Estádio do } \\
\text { Maracanã }\end{array}$ & 79.000 & 203.463 & Reforma & 461.6 milhões & 59.004 \\
\hline 11 & Salvador & Arena Fonte Nova & 52.048 & 176.500 & Novo & 302.9 milhões & 51.185 \\
\hline 12 & São Paulo & Arena de Itaquera & 65.807 & 198.000 & Novo & 505.6 milhões & 57.420 \\
\hline & Total & $\begin{array}{l}12 \text { Arenas / } \\
12 \text { Cidades }\end{array}$ & 666.077 & $\begin{array}{c}1.978 .44 \\
5 \\
\end{array}$ & $\begin{array}{l}5 \text { Reformas } \\
7 \text { Novos }\end{array}$ & 3.671 bilhões & 573.749 \\
\hline & Média & - & 55.506 & 164.870 & - & $306 \mathrm{mil}$ & 47,8 \\
\hline
\end{tabular}

Fonte: Adaptado de CO2Zero (2012) e Tóffano (2013). 


\subsection{Copa do Mundo FIFA ${ }^{T M}$ Brasil 2014}

A Copa do Mundo FIFA ${ }^{T M}$ Brasil 2014 foi a vigésima edição do torneio, tendo pela segunda vez o Brasil como sede (a outra foi em 1950). Sessenta e quatro jogos foram disputados por 32 países, entre os dias 12 de junho e 13 de julho. O público total do evento foi de 3.429 .873 pessoas e as 64 partidas tiveram uma média de 53.592 torcedores por arena.

\section{Construções e Reformas de Arenas}

Doze cidades brasileiras foram anfitriãs e disponibilizaram um estádio, cada uma. O custo médio de cada uma das doze arenas foi de US\$306 milhões (um detalhamento maior é encontrado na Tabela 5), cada assento custou, aproximadamente, US\$ 5.511,37, e emitirão, em um ciclo de vida de 30 anos, uma média de $47.8 \mathrm{tCO}_{2} \mathrm{e}$.

\section{Transportes e Demais Infraestruturas}

O Brasil apresenta um território de grandes dimensões com $8.515 .767 \mathrm{~km}^{2}$ de área. Porém, assim como a África do Sul, carente de transportes de massa mais qualificados, como trens de alta velocidade e de uma extensa rede metroferroviária; o que o faz altamente dependente do sistema rodoviário e aéreo para o transporte de passageiros e de cargas. Sua matriz energética é a mais limpa dos três, tendo como base, seus recursos hídricos (Ernst \& Young, 2010).

A Tabela 6 apresenta um detalhamento maior dos dados de transporte por nível nacional e internacional. Nela também podem ser encontrados os valores correspondentes as demais infraestruturas necessárias para a realização da Copa do Mundo de 2014. Cabe ressaltar que mesmo o Brasil apresentando a utilização de biocombustíveis em sua matriz energética, as dimensões territoriais continentais potencializaram as emissões de GEE.

A construção e a busca por projetos sustentáveis, para o Mundial de 2014, criou imensas oportunidades de ganhos ambientais e de redução de emissões de GEE. Principalmente, pelo estímulo oriundo dos financiamentos bancários, o que condicionou o acesso à obtenção de certificações ambientais, através de organismos internacionais, para estas arenas/estádios novos, ou reformados (Tóffano, 2013).

Em 2007, quando o Brasil foi escolhido, a neutralização dos GEE oriundos da Copa de 2014 era uma diretriz bem clara, o país buscava fazer a maior "Copa Verde" da história (CO2Zero, 2012). Todavia, a falta de recursos específicos, de planejamento adequado e de capital humano especializado, nas cidades-sede, podem ter comprometido o atendimento destas diretrizes propostas. Os dados oficiais totais, no entanto, ainda não foram divulgados. Com isso, enquanto a neutralização do carbono pode ser uma oportunidade de ganho de imagem para o país, assim como de investimentos mais limpos no caminho de uma economia de baixo carbono, o risco de se comprometer e não cumprir tal meta deve ser igualmente considerado. Contudo, o Brasil, em dados já divulgados, poderá ter a primeira Copa do Mundo com doze estádios com a certificação norte- 
americana LEED de sustentabilidade. Sete arenas até o momento já receberam o selo verde. Em Fortaleza, no Ceará, por exemplo, 90 toneladas de lixo recolhidas durante a Copa, no Castelão e nas áreas dedicadas a torcedores foram direcionadas para a reciclagem e tiveram uma destinação final correta (Portal Brasil, 2014).

Na próxima Seção, após a apresentação individual das emissões de GGE por Copa do Mundo, os valores relativos à construção/reforma de estádios/arenas; transportes; e demais infraestruturas são comparados entre si.

\section{Resultados e discussões}

De forma a facilitar a compreensão desta Seção, um quadro-síntese foi elaborado com os resultados mais expressivos de todas as Copas do Mundo entre 2006 e 2014 (Tabela 7). Inicialmente, ao se comparar os três Mundiais, constatou-se que os valores de GEE emitidos em $\mathrm{tCO}_{2} \mathrm{e}$, por estádios, é muito semelhante, (Alemanha: 549.597 / África do Sul: 479.811 / Brasil: 573.749) sem nenhuma diferença significativa. Os valores apenas variam em função das capacidades específicas e do número de subsedes de cada país. Grande parte dos estádios destes três mundiais teve algum tipo de preocupação com a sustentabilidade ambiental durante sua concepção, projeto, ou apresenta(m)(rão) ao longo de sua gestão pós-Copa.

Tabela 6: Emissões de $\mathrm{CO}_{2} \mathrm{e}$ de transportes e demais infraestruturas da Copa 2014.

\begin{tabular}{l|c}
\hline \multicolumn{1}{c}{ Emissões Estimadas (toneladas de CO2e) } \\
\hline Setores & Brasil 2014 \\
\hline $\begin{array}{l}\text { Transporte Internacional } \\
\text { (Para deslocamentos até o território do país-sede). }\end{array}$ & 2.764 .533 \\
\hline $\begin{array}{l}\text { Transporte Local } \\
\text { (Para deslocamentos dentro do território do país-sede). }\end{array}$ & 2.031 .649 \\
\hline $\begin{array}{l}\text { Construção } \\
\text { (Utilização de estádios e infraestrutura no período da Copa do Mundo). }\end{array}$ & 14.529 \\
\hline $\begin{array}{l}\text { Consumo de energia } \\
\text { (Estádios e infraestrutura no período da Copa do Mundo) }\end{array}$ & 13.806 \\
\hline Total das emissões com transportes e demais infraestruturas & $\mathbf{4 . 8 2 4 . 5 1 7}$ \\
\hline
\end{tabular}

Fonte: Adaptado de CO2Zero (2012). 
Tabela 7: Comparativo das emissões de $\mathrm{CO}_{2} \mathrm{e}$, por setor, nos Mundiais de 2006, 2010 e 2014

\begin{tabular}{|c|c|c|c|}
\hline \multirow[b]{2}{*}{ Setores } & \multicolumn{3}{|c|}{ Emissões Estimadas (toneladas de $\mathrm{CO}_{2} \mathrm{e}$ ) } \\
\hline & Alemanha 2006 & África do Sul 2010 & Brasil 2014 \\
\hline $\begin{array}{l}\text { Transporte Internacional } \\
\text { (para deslocamentos até o } \\
\text { território do país-sede). }\end{array}$ & $2.027 .320^{(1)}$ & $1.856 .589^{(4)(3)}$ & $2.764 .533^{(6)}$ \\
\hline $\begin{array}{l}\text { Transporte Local } \\
\text { (para deslocamentos dentro do } \\
\text { território do país-sede). }\end{array}$ & $72.680^{(2)(5)}$ & $524.538^{(4)(3)}$ & $2.031 .649^{(6)}$ \\
\hline $\begin{array}{l}\text { Construção (utilização de estádios } \\
\text { e infraestrutura no período da } \\
\text { Copa do Mundo). }\end{array}$ & $4.600^{(2)(5)}$ & $15.359^{(4)(3)}$ & $14.529^{(6)}$ \\
\hline $\begin{array}{l}\text { Consumo de energia (estádios e } \\
\text { infraestrutura no período da Copa } \\
\text { do Mundo) }\end{array}$ & $2.760^{(2)(5)}$ & $16.637^{(4)(3)}$ & $13.806^{(6)}$ \\
\hline $\begin{array}{l}\text { Construção/Reforma de estádios } \\
\text { (refere-se à utilização em um ciclo } \\
\text { de vida estabelecido de } 30 \text { anos) }\end{array}$ & $\begin{array}{c}549.597 \\
(\text { Tabela } 1)\end{array}$ & $\begin{array}{c}479.811 \\
\text { (Tabela 3) }\end{array}$ & $\begin{array}{l}573.749 \\
(\text { Tabela 5) }\end{array}$ \\
\hline $\begin{array}{l}\text { TOTAL } \\
\text { (sem transporte internacional) }\end{array}$ & 629.637 & 1.036 .345 & 2.633 .733 \\
\hline $\begin{array}{l}\text { TOTAL }(\%) \\
\text { (valor correspondente ao } \\
\text { transporte local sem internac.) }\end{array}$ & $11,5 \%$ & $50,6 \%$ & $77,1 \%$ \\
\hline $\begin{array}{l}\text { TOTAL }(\%) \\
\text { (valor correspondente aos estádios } \\
\text { e a infraestrutura sem transporte } \\
\text { internacional) }\end{array}$ & $88,5 \%$ & $49,4 \%$ & $22,9 \%$ \\
\hline $\begin{array}{l}\text { TOTAL } \\
\text { (com transporte internacional) }\end{array}$ & 2.719 .594 & 2.892 .934 & 5.398 .266 \\
\hline $\begin{array}{l}\text { Área do território nacional } \\
\left(\mathrm{em} \mathrm{km}^{2}\right)\end{array}$ & 357.051 & 1.221 .037 & 8.515 .767 \\
\hline $\begin{array}{l}\text { Número de espectadores } \\
\text { (milhões) }\end{array}$ & 3,4 & 3,2 & 3,4 \\
\hline $\begin{array}{l}\text { Emissão média por espectador } \\
\left(\mathrm{tCO}_{2} \mathrm{e}\right)\end{array}$ & $\begin{array}{c}\mathbf{0 , 1 8} \\
\text { (sem considerar } \\
\text { transporte aéreo } \\
\text { internacional) }\end{array}$ & $\begin{array}{c}\mathbf{0 , 3 2} \\
\text { (sem considerar } \\
\text { transporte aéreo } \\
\text { internacional) }\end{array}$ & $\begin{array}{c}\mathbf{0 , 7 7} \\
\text { (sem considerar } \\
\text { transporte aéreo } \\
\text { internacional) }\end{array}$ \\
\hline
\end{tabular}

Fonte: Adaptado de ${ }^{(1)}$ Focus (2006); ${ }^{(2)}$ Hochfeld et al. (2006); ${ }^{(3)}$ Econ Pöyry AB (2009); ${ }^{(4)}$ Ernst \& Young (2010); ${ }^{(5)}$ Neto et al. (2011) e ${ }^{(6)}$ CO2Zero (2012).

Quanto às emissões de GEE associadas à infraestrutura (materiais, energia, etc.) necessárias, durante os 30 dias médios do evento, constata-se que os valores oriundos do Mundial de 2006 são, aproximadamente, cinco vezes menores que as emissões calculadas para as Copas do Mundo de 2010, na África do Sul e de 2014, no Brasil. Esta diferença se dá por uma maior preocupação com a racionalização de recursos empregados na construção, operação e manutenção das arenas utilizadas no Mundial europeu.

Agora, se os valores com as emissões de GEE dos complexos esportivos são similares, o mesmo não se pode afirmar da utilização de seus sistemas de transportes. Como informado, na metodologia, os valores referentes às emissões de GEE dos deslocamentos terrestres e aéreos (nacionais e internacionais) destes três países foram compilados das obras de Focus (2006); Hochfeld et al. (2006); Econ Pöyry AB (2009); Ernst \& Young (2010); Neto et al. (2011) e CO2Zero (2012) e estão listados na Tabela 7. 
A dimensão territorial do país é muito relevante neste item, quanto maior a área de um país e a distância média entre suas sedes, maior será o número de deslocamentos aéreos, ou terrestres. O Brasil pelas dimensões continentais é o maior poluidor dos objetos analisados. Quando estes valores são avaliados em percentagem, constata-se que 77,1\% das emissões de $\mathrm{CO}_{2}$ e do Mundial de 2014 foram provenientes do transporte; ao adicionar o transporte internacional este valor se eleva para quase $88,8 \%$. Ou seja, apesar da busca por uma "Copa Verde", desde 2006, quando o Programa Green Goal ${ }^{T M}$ entrou em operação e estes valores começaram a ser calculados, a Copa de 2014 foi a mais poluente das três amostras, mesmo que busque em suas diretrizes justamente o contrário.

A Rússia (sede da Copa do Mundo de 2018) é outro bom exemplo de país continental, já que apresenta suas cidades-sede mais dispersas do que países considerados pequenos como a Alemanha e o Catar (sede da Copa do Mundo de 2022). Outro fator relevante em transportes é o número destas cidades e o número de estádios disponibilizados em cada uma. Cidades como Doha, no Qatar, com seis estádios concentrados em uma única cidade emitirá menos GEE em deslocamentos, do que, por exemplo, o Brasil, que teve apenas uma arena em cada cidade-sede. Quanto maior a difusão de cidades-sede em um território nacional, maiores serão os deslocamentos aéreos e terrestres e consequentemente um volume maior de GEE é esperado.

Ao comparar as emissões de GEE destes três Mundiais, acentuam-se as diferenças na intensidade de $\mathrm{tCO}_{2} \mathrm{e}$ emitidos, observando-se um aumento significativo em função da dependência maior de estradas e do transporte aéreo. Assim, quanto mais distante da Europa, continente que sempre apresenta o maior número de países participantes de um Mundial, maior o número de deslocamentos internacionais e maiores serão as taxas de GEE. O Brasil, por apresentar suas principais cidades, em média, mais distantes que as da África do Sul, em relação à Europa, apresenta os maiores valores. A Alemanha é beneficiada por grande parte dos deslocamentos serem realizados por trens e não por aviões, em função de sua malha ampla e conectada à Europa. Uma malha integrada se torna um beneficio para a cidade e para a redução na emissão de GEE de qualquer anfitrião de megaeventos. Copas do Mundo, ou Olimpíadas, acabam apresentando grandes efeitos negativos para o meio ambiente e para a sociedade, caso estes valores na emissão de GEE não sejam mitigados com correto planejamento e a busca pela sustentabilidade (Ahmed \& Pretorius, 2010).

Como forma de tornar estes resultados mais factíveis, a emissão total de GEE, em $\mathrm{tCO}_{2} \mathrm{e}$, foi dividida pelo número estimado de espectadores, desconsiderando o transporte internacional. $\mathrm{O}$ saldo, a emissão média por espectador, é bastante expressivo, principalmente, pela pequena variação do número de espectadores totais, entre as diferentes sedes. Os valores praticamente duplicam a cada quatro anos (2006: 0,18 / 2010: 0,32 / 2014: 0,77) e permitem refletir sobre as expectativas para o próximo Mundial, na Rússia, em 2018, que apresenta 17.075.200 km², aproximadamente, o dobro da área territorial brasileira. Esta análise foi realizada desta forma, porque o Brasil apresenta uma taxa de emissões de GEE de transporte internacional maior do que a soma dos transportes internacional e local de cada um dos outros países em análise. O que tornaria estas diferenças ainda maiores. 
Por fim, considerando as emissões totais oriundas dos transportes local e internacional, mais as emissões das demais infraestruturas necessárias, comparativamente com as emissões oriundas para apenas um ano de um ciclo de vida de 30 anos das emissões em estádios, formulou-se a Tabela 8. Nela, a Alemanha emitiu 115 vezes menos poluentes, em um ano, com a construção/reforma de arenas do que com um mês de deslocamentos de sua Copa do Mundo. A África do Sul emitirá 151 vezes menos GEE com a construção/reforma de arenas (analisando, anualmente, o ciclo de vida de 30 anos dessas edificações) do que com um mês de evento e seus intensos deslocamentos. No Brasil, por sua vez, este valor é 252 vezes menor. Visivelmente, estes valores elevados, na emissão de GEE na atmosfera, são decorrentes do translado internacional de torcedores e de delegações até o país sede. Daí, a importância de um correto planejamento de transportes nas cidades em questão, entre elas e se possível, entre diferentes países.

Assim, o setor de transportes e mobilidade urbana deve ser prioritário para investimentos destinados à realização de megaeventos esportivos sustentáveis, em especial Copas do Mundo, para qualquer país, pois só assim, será possível minimizar de forma real a emissão de GEE na atmosfera, maximizar o conforto de visitantes e viabilizar financeiramente estes eventos. Como resultado, fica evidenciada a necessidade fundamental de um melhor processo de planejamento, governança e gestão de empreendimentos e atividades para os próximos Mundiais, para que estes não sejam apenas um projeto de "Copa Verde", mas sim, de fato, um evento eficaz na gestão, no planejamento e no monitoramento de recursos financeiros destinados a reduzir a emissão de GEE na atmosfera.

Tabela 8: Comparativo das emissões de $\mathrm{tCO}_{2} \mathrm{e}$, ao ano, dos Mundiais de 2006 a 2014.

\begin{tabular}{|c|c|c|c|c|}
\hline & $\begin{array}{l}\text { Emissão total } \\
\text { em tCO } \mathrm{CO}_{2} \mathrm{em} \\
\text { estádios } \\
\text { (ciclo de vida } \\
\mathbf{3 0} \text { anos). } \\
\end{array}$ & $\begin{array}{l}\text { Emissão total } \\
\text { em tCO em em } \\
\text { estádios/arenas } \\
\text { (ao ano de ciclo } \\
\text { de vida). }\end{array}$ & $\begin{array}{l}\text { Emissão total em } \mathrm{HCO}_{2} \mathrm{e} \\
\text { com transportes e } \\
\text { infraestrutura necessária } \\
\text { para um mês de evento da } \\
\text { Copa do Mundo. }\end{array}$ & $\begin{array}{l}\text { Proporção da } \\
\text { emissão de GEE em } \\
\text { um mês de Copa } \\
\text { sobre emissão anual } \\
\text { do total de arenas. }\end{array}$ \\
\hline Alemanha & 549.597 & 18.319 & 2.107 .360 & $115 \mathrm{x}$ mais poluente \\
\hline África do Sul & 479.811 & 15.994 & 2.413 .123 & $151 \times$ mais poluente \\
\hline Brasil & 573.749 & 19.125 & 4.824 .517 & $252 \times$ mais poluente \\
\hline
\end{tabular}

\section{Considerações finais}

Este artigo, além de apresentar que a emissão de gases do efeito estufa oriundos dos sistemas de transporte é muito maior que aquela proveniente da construção/reforma de arenas/estádios de futebol, ressaltou que a busca por "Copas Verdes", "Copas Limpas", ou simplesmente, Copas do Mundo mais sustentáveis, tem como seu maior desafio o correto planejamento do sistema de transporte e a escolha, principalmente, de meios de transporte menos poluentes nos deslocamentos internacionais e entre cidades do(s) país(es) anfitrião(ões).

Constatou-se que quanto maior o número de cidades-sede de um país a receber jogos de futebol, maior é a emissão de GEE e que esta é proporcional à dispersão no território nacional. Assim, países como o Brasil, na Copa de 2014 (12 sedes, 12 estádios) e a Rússia, para a Copa de 2018 (11 sedes, 12 estádios), com territórios muito extensos, sofrem mais com os efeitos destas emissões, que

ENGEVISTA, V. 18, n. 2, p. 436-454, Dezembro 2016. 
países menores como a Alemanha, em 2006 (12 sedes, 12 estádios), e o Catar (07 sedes, 12 estádios), em 2022. Copas do Mundo, ou outros campeonatos, com mais de um país sede, a exemplo do Mundial de 2002, compartilhado entre a Coreia do Sul e o Japão, com dez sedes em cada país e com constantes deslocamentos internacionais, são uma preocupação a mais na busca pela sustentabilidade.

O desenvolvimento econômico de cada uma destas nações também é relevante nestas análises. Países centrais como a Alemanha e o Japão com ampla cobertura e rede de transportes e presença, principalmente, de uma rede metroferroviária de grandes proporções, com direito a trens de passageiros com qualidade e de alta velocidade, entre importantes cidades, diminuem a necessidade da utilização e dependência do transporte aéreo. Em compensação países periféricos como o Brasil e a África do Sul ainda se apresentam incipientes na oferta de transportes de massa e acabam apresentando, assim, Mundiais mais poluentes.

O Brasil que tinha por objetivo, em sua candidatura a 2014, ter a "Copa mais sustentável” de todos os tempos, pelas projeções apresentadas, teve o Mundial com o maior número de emissões das últimas três edições. Para isto, vários motivos podem ser destacados: a (re)construção de novos estádios foram sete, no total, com outras cinco grandes reformas, mais que nas duas Copas anteriores, mesmo que todos tenham preocupações com a sustentabilidade, em suas concepções; o atraso no processo adequado de planejamento, governança e gestão de empreendimentos e atividades correlacionadas, a exemplo do adiamento da inauguração do trem de alta velocidade, entre o Rio de Janeiro e Campinas, passando por São Paulo; a exclusão de várias obras de mobilidade da matriz de projetos para 2014, a exemplo do monotrilho de Manaus e o Veículo Leve Sobre Trilhos (VLT) de Brasília; e principalmente, a dispersão em um território continental de suas sedes, dependentes do sistema aéreo para rápidas conexões. Esta grande dependência brasileira de deslocamentos aéreos, contribuiu para que o Mundial de 2014 fosse o maior emissor de GEE, até hoje.

Como sugestões de novos estudos derivados deste trabalho, citam-se: pesquisas para propor medidas de mitigação para os danos causados pelos meios de transporte; formas de minimizar a produção de GEE da construção de novas arenas/estádios de futebol; e mecanismos para estimar as reduções provenientes destas medidas. Estas contribuições auxiliariam de forma plena no êxito de novos estudos comparativos e das relações estabelecidas neste artigo. 
AGRADECIMENTOS: Registra-se o apoio do CNPq e da CAPES ao desenvolvimento desta pesquisa.

\section{Referências bibliográficas}

AHMED, F.; PRETORIUS, L. 2010. Mega-events and Environmental Impacts: The 2010 FIFA World Cup in South Africa. Alteration 17(2): 274-296.

BISMARCHI, L. F. 2011. Sustentabilidade e Inovação no Setor Brasileiro da Construção Civil: Um Estudo Exploratório Sobre a Implantação da Política Pública Baseada em Desempenho. Dissertação de Mestrado em Ciência Ambiental. Universidade de São Paulo. São Paulo-SP. 173 p.

CO2Zero - EDIÇÃO DE INFORMAÇÕES E SERVIÇOS LTDA. 2012. Brasil 2014 - Estudo de Impacto de Emissões em $\mathrm{CO}_{2}$ Equivalente. São Paulo-SP, 19p.

COLLINS, A.; JONES, C.; MUNDAY, M. 2009. Assessing the Environmental Impacts of Mega Sporting Events: Two Options? Tourism Management, 30: 828-37.

ECON PÖYRY AB. 2009. Feasibility Study for a Carbon Neutral 2010 FIFA World Cup in South Africa. Norwegian Government (NORAD), Department of Environmental Affairs and Tourism, fev. 2009.

Disponível

em: <http://www.norway.org.za/NR/rdonlyres/3E6BB1B1FD2743E58F5B0BEFBAE7D958/114457/Feas ibilityStudyforaCarbonNeutral2010FIFAWorldCup.pdf >. Acesso em: 27 jul. 2015.

ERNST \& YOUNG. 2010. Brasil Sustentável - Impactos Socioeconômicos da Copa do Mundo 2014. Disponível em: < http://fgvprojetos.fgv.br/sites/fgvprojetos.fgv.br/files/estudo_9.pdf >. Acesso em: 26 jan. 2016.

FIFA - FÉDÉRATION INTERNATIONALE DE FOOTBALL ASSOCIATION. 2007. FIFA Football Stadiums: Technical recommendations and requirements. Zurich, Switzerland: FIFA, 248 p.

FOCUS. 2016. Green-Goal-Konzept sorgt für "grüne WM 2006”. In: Focus Online, 13 dec. 2006. Disponível em: <http://www.focus.de/sport/fussball/fussball-wm-green-goal-konzept-sorgt-fuergruene-wm-2006 aid 292398.html >. Acesso em: 20 fev. 2016

GÖSSLING, S.; HANNSON, C.; HORSTMEIER, O.; SAGGEL, D. 2002. Ecological Footprint Analysis as a Tool to Assess Tourism Sustainability. Ecological Economics, 43,199-211.

HOCHFELD, C.; STAHL, H. 2003. Green Goal - Environmental Objectives for the 2006 FIFA World Cup. Öko-Institut, Berlin, Alemanha mar.2003. Disponível em: < http://www.oeko.de/oekodoc/169/2003-044-en.pdf >. Acesso em: 17 jul 2015.

IOC - INTERNATIONAL OLYMPIC COMMITTEE. 2013. Sustainability Through Sport. Lausanne, Suisse: IOC, $102 \mathrm{p}$.

NETO, M. P. M.; OLIVEIRA, B. da C. P. O.; KISS, B. C. K. 2011. Sustentabilidade e a Copa do Mundo de 2014: Desafios e Oportunidades na Gestão das Emissões de Gases de Efeito Estufa. In Anais SIMPOI.

OC - ORGANIZING COMMITTEE FIFA WORLD CUP 2006. 2006. Green Goal - Legacy Report. Frankfurt, Alemanha. $120 \mathrm{p}$.

ONU - ORGANIZAÇÃO DAS NAÇÕES UNIDAS. 2005. Protocolo de Quioto à Convenção Quadro das Nações Unidas sobre Mudanças Climáticas. Quioto. Disponível em < http://www.mct.gov.br/upd blob/0012/12425.pdf > Acesso em: 14 jan. 2016.

POLOKWANE MUNICIPALITY. 2009. Greening Plan for the 2010 Soccer World Cup. Pretoria, Província de Limpopo, África do Sul Mar. Edição: Future Works. 54 p.

PORTAL BRASIL. 2014. Ceará Coleta Mais de 90 Toneladas de Resíduos Para Reciclagem na Copa. In: Portal BRASIL, 24 jul. Disponível em: < http://www.brasil.gov.br/meioambiente/2014/07/ceara-tem-mais-de-90-toneladas-de-residuos-para-reciclagem-durante-copa $>$. Acesso em: 07 jan. 2016.

SILVA, V. G. da. 2007. Metodologias de Avaliação de Desempenho Ambiental de Edifícios: Estado Atual e Discussão Metodológica. In: Habitação mais Sustentável. Documento 5. Projeto FINEP 2386/04: Tecnologias para construção habitacional mais sustentável. São Paulo, 60p.

TÓFFANO, R. 2013. Sustentabilidade em Estádios de Futebol: O Caso da Arena Pantanal em Cuiabá-MT. Dissertação de Mestrado em Engenharia de Edificações e Ambiental. Área de Concentração: Construção Civil. Universidade Federal de Mato Grosso. Cuiabá, Mato Grosso, 305 p.

ENGEVISTA, V. 18, n. 2, p. 436-454, Dezembro 2016. 